\title{
ANÁLISE DE SEÇÕES COMPLEMENTARES EM LIVROS DIDÁTICOS DE CIÊNCIAS: POTENCIALIDADES PARA DISCUSSÕES SOCIOCIENTÍFICAS
}

\author{
Analysis of complementary sections in the science didactic book: potentialities to \\ socio-scientific discussions
}

\author{
Análisis de secciones complementarias en libros didácticos de ciencias: \\ potencialidades para discusiones sociocientíficas
}

\author{
Karolina Martins Almeida e Silva* \\ Verenna Barbosa Gomes* \\ Ludmylla Élfrida Cardoso de Paula*
}

\begin{abstract}
Resumo
Os pressupostos da Educação Ciência-Tecnologia-Sociedade (CTS) para o ensino de ciências com vistas à formação sociopolítica estão calcados na problematização da visão cientificista e instrumental da ciência e da tecnologia. Por outro lado, considera-se que o Livro Didático (LD) é um importante instrumento para o planejamento didático-pedagógico de professores na abordagem dos conteúdos científicos. Frente a isso, o presente estudo teve por objetivo identificar potencialidades de seções complementares de LDs de ciências para fomentar discussões sociocientíficas em aulas no Ensino Médio. Deste modo, a metodologia da pesquisa foi estruturada nas seguintes etapas: 1) leitura do Guia do LD (2014) para os componentes curriculares de Biologia, Física e Química; 2) identificação dos LDs com seções complementares intituladas "CTS"; 3) leitura sistemática e análise textual discursiva das seções identificadas e; 4) evidenciação das categorias correlacionadas às dimensões CTS. A partir das análises, constatou-se que os textos potencialmente incitam discussões sociocientíficas por abarcarem diversos aspectos das dimensões CTS. No entanto, cabe mencionar que o direcionamento dado pelos professores durante o processo discursivo de sala de aula é fundamental para ampliar as compreensões dos estudantes em uma perspectiva problematizadora, contextualizada e interdisciplinar.
\end{abstract}

PALAVRAS-CHAVE: Educação CTS. Livro Didático. Ensino de Ciências

\begin{abstract}
The assumptions of Science-Technology-Society (STS) for the science education with a view to socio-political formation are based on the problematization of the scientific and instrumental vision of science and technology. On the other side, it is considered that the Didactic Book (DB) is an important instrument for the didactic-pedagogical planning of teachers in the approach of scientific contents. In view of this, the present study aimed to identify the potentiality of complementary sections of science DBs to foster socio-scientific discussions in classes in High School. Thus, the

\footnotetext{
* Doutora em Educação (UnB). Professora Adjunta do Curso de Licenciatura em Biologia e do Programa de Pós-Graduação em Ensino de Ciências da Universidade Federal do Tocantins (UFT) - Campus de Araguaína. Coordenadora de Área do PIBID-Biologia. E-mail: karolinaeducabio@gmail.com; karolina.martins@uft.edu.br.

* Doutoranda do Programa de Pós-Graduação em Educação em Ciências (UnB). Professora do Curso de Licenciatura em Química - Campus de Araguaína. E-mail: verennabg1 @ gmail.com.

* Professora de Ciências do CAC - Centro de Apoio à Criança Jorge Humberto de Camargo, Araguaína -TO. E-mail: ludmyllaelfrida19@gmail.com.
} 
research methodology was structured in the following stages: 1) reading the DB Guide (2014) for the curricular components of Biology, Physics and Chemistry; 2) identification of DBs with complementary sections entitled "STS"; 3) systematic reading and discursive textual analysis of the sections identified and; 4) disclosure of categories correlated to STS dimensions. After the analysis process, it was verified that the texts potentially incite socio-scientific discussions because they cover several aspects of the STS dimensions. However, it should be mentioned that the direction given by teachers during the discursive process of the classroom is fundamental to broaden students' understandings in a problematizing, contextualized and interdisciplinary perspective.

KEYWORDS: STS Education. Textbook. Science education

\section{Resumen}

Las presuposiciones de la Educación-Ciencia-Tecnología-Sociedad (CTS) para la enseñanza de ciencias con el objetivo de la formación sociopolítica, están soportadas en las cuestiones de la visión científica e instrumental de la ciencia y tecnología. Por otro lado, se considera que el Libro Didáctico (LD) es un valorable instrumento para la planificación didáctico-pedagógico de los profesores en el abordaje de los contenidos científicos. Con eso, la presente investigación tuvo el objetivo de identificar la capacidad de las secciones complementarias de LDs de ciencias para fomentar discusiones sociocientíficas en clases en la Enseñanza Media. De ese modo, la metodología de la investigación fue estructurada en las siguientes etapas: 1) lectura de la Guía del LD (2014) para los componentes curriculares de Biología, Física y Química; 2) identificación de los LDs con secciones complementarias tituladas "CTS"; 3) lectura sistemática y análisis textual discursivo de las secciones identificadas y; 4) demostración de las categorías correlacionadas a las dimensiones CTS. A partir de los análisis, se constató que los textos potencialmente incitan discusiones sociocientíficas por abarcaren diversos aspectos de las dimensiones CTS. Sin embargo, cabe mencionar que el encaminamiento dado por los profesores durante el proceso discursivo de aula es fundamental para ampliar las comprensiones de los estudiantes en una perspectiva cuestionadora, contextualizada e interdisciplinaria.

PALABRAS CLAVE: Educación CTS. Libro Didáctico. Enseñanza de Ciencias

\section{INTRODUÇÃO}

As inter-relações Ciência-Tecnologia-Sociedade $(\mathrm{CTS})^{1}$ são a base constituinte para a Educação CTS, que é defendida por educadores e pesquisadores em áreas diversas. Esta, por sua vez, assume que a sociedade, além de ter acesso às informações sobre o desenvolvimento da ciência e da tecnologia, também deverá ter condições de avaliar e participar das decisões que interferem o seu contexto. Como afirma Bazzo (1998), "o cidadão merece aprender a ler e entender - muito mais do que conceitos estanques - a ciência e a tecnologia, com suas implicações e consequências, para poder ser elemento participante nas decisões de ordem política e social” (p. 34).

\footnotetext{
1 Ao considerar que esse movimento incorpora uma perspectiva de reflexão sobre questões ambientais, Santos (2008) ressalta que, nas décadas de 1970 e 1980, ele centrou-se, sobretudo, nas consequências ambientais, "razão pela qual muitos também adotam a sigla CTSA (Ciência-Tecnologia-SociedadeAmbiente), que acrescenta o ambiente como mais um foco de análise nas inter-relações da tríade CTS" (SANTOS, 2008, p.118). Neste trabalho optamos por adotar a sigla "CTS".
} 
Os pressupostos da Educação CTS para o ensino de ciências, com vistas à participação sociopolítica ${ }^{2}$ estão calcados na problematização da visão cientificista e instrumental da ciência e tecnologia. Busca-se resgatar as implicações políticas, econômicas, sociais, ambientais, culturais, éticas e morais, ou seja, os Aspectos Sociocientíficos (ASC) necessários para a compreensão do desenvolvimento científicotecnológico em um processo histórico, evidenciando diferentes interesses e ideologias (STRIEDER, 2012; SANTOS; MORTIMER, 2009).

Ao se propor um currículo com ênfase na abordagem das inter-relações CTS, autores, como Santos e Mortimer (2002), Bazzo, Von Linsingen e Pereira (2003), Nascimento e Von Linsingen (2006), entre outros, apontam para a necessidade de uma proposta de trabalho interdisciplinar e contextualizada que contemple essas relações de modo a contribuir para um maior significado ao aprendizado das disciplinas do núcleo das ciências naturais. $\mathrm{O}$ objetivo é formar uma sociedade que questione os impactos do desenvolvimento científico e tecnológico no seu contexto social, de modo a perceber que certas atitudes não condizem com os interesses da maioria, mas sim de uma minoria dominante.

De acordo com Santos e Mortimer (2002), currículos de ciências com ênfase em CTS são aqueles que tratam das relações entre explicação científica, planejamento tecnológico e solução de problemas e/ou tomada de decisão sobre temas práticos de importância socioambiental. A abordagem dos conceitos científicos, de suas aplicações tecnológicas e consequências sociais por meio de temas de natureza problematizadora tendem a favorecer a introdução de uma série de atividades relacionadas à tomada de decisão que exploram os aspectos ambientais, políticos, econômicos, éticos, sociais e culturais em sua multidimensionalidade.

Os documentos curriculares oficiais são importantes elementos de análise e discussão sobre o contexto curricular brasileiro e, por sua vez, representam as políticas públicas de reforma educacional desde a promulgação da Lei de Diretrizes e Bases para a Educação Nacional - LDBEN de 1996. Nesse sentido, a análise dessas orientações indica os direcionamentos sobre como a Educação Científica vem sendo delineada, e também quais os desafios associados ao desenvolvimento de práticas educativas CTS no Brasil (ver, por ex.: STRIEDER et al. 2016; ROEHRIG; CAMARGO, 2014; SILVA, 2010).

Em estudos realizados por Strieder et al. (2016), sobre os documentos curriculares oficiais para o ensino de ciências no Ensino Médio, em específico sobre as sinalizações CTS, os autores consideraram que todos sinalizam objetivos e direcionamentos à educação CTS. No entanto, ressaltam que também apresentam lacunas e ambiguidades sobre conceitos como os de cidadania, interdisciplinaridade, contextualização e abordagem de temas, dando margem a inúmeras interpretações, que podem contribuir para práticas educacionais que se afastam de uma perspectiva crítica de Educação CTS.

Embora seja notória a indicação, nos documentos curriculares oficiais, para abordagem das inter-relações CTS, no ensino de ciências, são evidentes a carência e a dificuldade dos professores de ciências na realização de propostas curriculares de natureza

\footnotetext{
2 Nós nos apoiamos nas considerações de Linhares e Reis (2018) sobre "formação sociopolítica fundamentada". Essa formação é orientada por ações didático-pedagógicas que objetivamente permitam que os educandos tenham uma imagem mais real do desenvolvimento científico-tecnológico e que os capacite por meio de conhecimentos e competências necessários para tomada de decisões sobre questões controversas de cunho social e ambiental.
} 
CTS (ver, por ex.: MUENCHEN; AULER, 2007; RICARDO, 2007; FORGIARINI; AULER, 2009; SILVA, 2010).

Considerando o LD um orientador da prática docente, desde o desenvolvimento do conteúdo até o processo avaliativo, ele se torna, portanto, um material de referência para o trabalho do professor. Nesse sentido, o LD é um importante instrumento para o planejamento didático-pedagógico de professores com vistas à abordagem dos conteúdos científicos de forma ampla e por meio de estratégias metodológicas advindas de ações contextualizadas e interdisciplinares. Um ponto importante a ser destacado é que, mesmo diante dos avanços tecnológicos e da enorme variedade de materiais didáticos atualmente disponíveis no mercado, o LD não perdeu a sua centralidade, continuando a ser o recurso mais utilizado pelos professores para o ensino de ciências (CARNEIRO; SANTOS; MÓL, 2005).

Frente a essas considerações sobre a centralidade curricular e didático-pedagógica atribuída ao LD, a presente pesquisa toma-o como objeto de estudos. Em específico, escolhemos trabalhar com a análise de suas seções complementares porque, segundo Abreu, Gomes e Lopes (2005), há uma tendência dos LD de ciências em trazer reflexões acerca da ciência e da tecnologia em tais espaços. Deste modo, nos questionamos: que direcionamentos são apresentados nas seções complementares dos LD de ciências para o Ensino Médio no que compete à abordagem das inter-relações CTS? De que forma as seções complementares intituladas CTS colaboram e se constituem potenciais instrumentos para discussões sociocientíficas?

Diante disso, consideramos pertinente a análise das seções complementares, tanto para identificar os direcionamentos dos autores de LD de ciências sobre o enfoque CTS, como também ampliar as discussões sobre o direcionamento curricular de uma Educação CTS com vistas à formação sociopolítica. Portanto, a análise apresentada, neste artigo, tem por objetivos: a) identificar e verificar a relação entre os aspectos sociocientíficos (ASC) apresentados nos textos das seções intituladas CTS e; b) delinear a potencialidade dos textos para promover discussões sociocientíficas em suas diversas dimensões.

\section{O livro didático de Ciências e o enfoque CTS}

Inicialmente, posicionaremos o nosso entendimento acerca do $\mathrm{LD}$, a partir da definição de Bittencourt (2004), sendo, portanto, um objeto de múltiplas facetas: produto cultural; mercadoria ligada ao mundo editorial e dentro da lógica do mercado capitalista; suporte de conhecimentos e de metodologias de ensino de diversas disciplinas e conteúdos escolares; e, ainda, material que veicula valores, ideologias ou culturas.

Destacamos também as funções do LD delineadas por Choppin (2004), sendo elas: função referencial também nomeada de função curricular ou programática, cujo foco está no suporte dos conteúdos escolares; função instrumental, propondo o método de ensino, os exercícios e atividades para desenvolver competências e habilidades; função documental, contendo elementos textuais e icônicos que, a partir da observação, podem vir a desenvolver a criticidade do aluno; função ideológica/cultural, transmitindo valores e ideologias. Embora essas funções sejam bem definidas, o autor chama a atenção para o fato de que elas "podem variar consideravelmente segundo o ambiente sociocultural, a época, as disciplinas, os níveis de ensino, os métodos e as formas de utilização" (CHOPPIN, 2004, p. 553). 
Nesse caminho, é importante compreendermos a constituição histórica do LD enquanto política pública e instrumento de análise sobre o contexto do ensino de ciências no Brasil. Assim, ao longo das duas últimas décadas, o LD se tornou objeto de estudo de muitas pesquisas sobre o ensino de ciências, estas voltadas à análise de seus conteúdos; veiculação de ideologias; histórico sobre sua veiculação do LD de ciências; análise de critérios de avaliação do LD; concepções acerca da natureza da ciência, dentre outras.

Tal atribuição se dá pelo fato de que, tanto a comunidade acadêmica, quanto os idealizadores de políticas públicas no Brasil reconhecerem a relevância e as influências da utilização desse material didático no contexto escolar. Inclusive, os últimos mencionados transformaram um conjunto de políticas de assistência estudantil para distribuição gratuita de livros a alunos de escolas públicas, que são realizadas desde 1938, e como política pública a partir da criação do Programa Nacional do Livro Didático (PNLD) em 1985, vigente até hoje com modificações. O PNLD está estruturado nas seguintes etapas: elaboração de Edital de Convocação; inscrição; triagem; pré-análise; avaliação pedagógica; elaboração do Guia de Livros Didáticos (GLD) e encaminhamento para as escolas; escolha das obras pelas escolas; negociação por parte do Fundo Nacional de Desenvolvimento da Educação (FNDE), com as editoras; produção e distribuição das obras (HÖFLING, 2000; MACHADO; MOL; ZANON, 2012).

O PNLD foi instituído por meio do Decreto $\mathrm{n}^{\circ}$. 91.542/1985 inicialmente para o ensino fundamental regular e, em 2004 por meio do Programa Nacional do Livro Didático para o Ensino Médio (PNLEM). Em 2007 o PNLEM passou a distribuir os LD de Biologia, e em 2008 de Química e Física. A partir da publicação do Decreto 7.084/2010, foi regulamentada a avaliação e distribuição de materiais didáticos para toda a educação básica. Trata-se de um importante avanço frente ao PNLD, visto que reforça e viabiliza a avaliação, compra e distribuição de livros didáticos para a escolarização básica em todo o Brasil (BRASIL, 2015).

A publicação dos Parâmetros Curriculares Nacionais - PCNs (BRASIL, 1998) indica orientações sobre o entendimento e abordagem dos conteúdos veiculados em LDs de ciências. Vasconcelos e Souto (2003) ressaltam que a definição de "Ciência" apresentada nos PCNs foi um importante indicativo para a reconfiguração de LDs no que compete à apresentação, organização e abordagem dos conteúdos científicos. No entanto, os autores apontam que, ao se realizar "[...] uma leitura atenta da maioria dos livros de ciências disponíveis no mercado brasileiro, entretanto, revela uma disposição linear de informações e uma fragmentação do conhecimento que limitam a perspectiva interdisciplinar” (p. 94).

Para Megid-Neto e Fracalanza (2003), os LDs de ciências devem considerar explícita ou implicitamente as concepções de Ciência, Ambiente, Educação, Sociedade, das relações CTS, entre tantas outras concepções de base pertinentes ao campo da Educação em Ciências, as quais determinam a própria concepção de LD e de sua relevância educacional. Os referidos autores afirmam que as coleções didáticas de ciências não sofreram mudança substancial nos aspectos essenciais que derivam de fundamentos conceituais, os quais determinam as peculiaridades do ensino no campo das Ciências Naturais.

Em observância aos critérios avaliativos para os LDs de Ciências da Natureza (Biologia, Física e Química), algumas modificações foram instituídas pelo PNLD - Ensino 
Médio $(2015)^{3}$ que visaram atender ao que preconizam os documentos curriculares oficiais mais recentes. Sobre a escolha das obras que compõem os GLDs em relação às propostas curriculares, o documento explicita que:

\begin{abstract}
As unidades escolares devem orientar a definição de toda proposição curricular fundamentada na seleção dos conhecimentos, componentes, metodologias, tempos, espaços, arranjos alternativos e formas de avaliação, tendo presente: I as dimensões do trabalho, da ciência, da tecnologia e da cultura como eixo integrador entre os conhecimentos de distintas naturezas, contextualizandoos em sua dimensão histórica e em relação ao contexto social contemporâneo; [...] (BRASIL, 2015, p. 10, grifo nosso).
\end{abstract}

Os indicativos mencionados na citação anterior estão em consonância com o que os documentos curriculares preconizam em referência ao ensino de ciências e, por sua vez, denotam os pressupostos do enfoque CTS por indicar a relação entre a ciência, tecnologia e sociedade. Assim, pressupõe a indicação sobre a integração entre os conhecimentos de naturezas distintas a partir das dimensões cultural e histórica em uma abordagem contextualizada.

Em relação aos critérios adotados para a avaliação dos LDs que compõem o GLD de Biologia (2014a), os mesmos foram elaborados a partir de uma articulação entre critérios eliminatórios comuns a todas as áreas, critérios eliminatórios específicos da área de Ciências da Natureza e suas Tecnologias e os do componente curricular Biologia constantes do Edital de Convocação 01/2013 (BRASIL, 2014a).

Dentre os critérios eliminatórios específicos da área de Ciências da Natureza sinalizados no GLD de Biologia, os quais indicam o enfoque CTS, destacamos: “[...] utiliza a contextualização e a interdisciplinaridade como premissas básicas para a organização didático-pedagógica dos assuntos e o desenvolvimento das atividades" (BRASIL, 2014a, p. 10). E, em relação aos critérios específicos ao componente curricular da Biologia: "[...] base em temas estruturadores, como origem e evolução da vida; identidade dos seres vivos e diversidade biológica; transmissão da vida, ética e manipulação genética interação entre os seres vivos e desses com o ambiente" (BRASIL, 2014a, p. 11).

Em relação ao GLD de Química (2014c), destacamos dois critérios relacionados ao enfoque CTS, a saber: a dimensão ambiental dos problemas contemporâneos e a apresentação do conhecimento químico de forma contextualizada. Tais indicadores expressam a preocupação com as questões socioambientais e a abordagem do conhecimento químico de forma contextualizada, considerando dimensões sociais, econômicas e culturais da vida humana, em detrimento de visões simplistas acerca do cotidiano (BRASIL, 2014c).

Diferente do GLD da Biologia e Química, os direcionamentos ao enfoque CTS são mais explícitos no documento referente aos LDs do componente curricular da Física. O mesmo apresenta como critério eliminatório específico a proposição de discussões sobre as relações entre ciência, tecnologia, sociedade e ambiente, de modo que as mesmas

\footnotetext{
3 Encontra-se em vigência o PNLD de 2019 na página do MEC (http://www.fnde.gov.br/programas/programas-do-livro/pnld/guia-do-livro-didatico/item/11986-escolhapnld-2019). No entanto, o GLD referente aos componentes curriculares de Ciências do Ensino Médio (Biologia, Física e Química) ainda está sendo elaborado/avaliado pela comissão técnica. Nesse sentido, optamos por abordar elementos referentes ao GLD do PNLD de 2015 ainda em vigor nas escolas públicas por meio dos LDs distribuídos.
} 
objetivam promover a formação de um cidadão capaz de apreciar e de posicionar-se criticamente diante das contribuições e dos impactos da ciência e da tecnologia sobre a vida social e individual (BRASIL, 2014b).

Deste modo, tendo em vista as sinalizações do enfoque CTS nos documentos curriculares, assim como no PNLD (BRASIL, 2014) e no GLD dos componentes curriculares de Biologia, Física e Química, elencamos, nos subtítulos que se seguem, as análises e discussões sobre o direcionamento dado por seus autores no que compete às discussões sociocientíficas.

\section{Encaminhamentos metodológicos}

Este estudo está centrado nos LDs para o ensino de Ciências da Natureza do Ensino Médio (Biologia, Física e Química). Para tanto, foram pré-estabelecidos os seguintes parâmetros para delimitação do material de análise: a) edições aprovadas pelo GLD (BRASIL, 2014) referentes ao PNLD (2015); b) volume referente ao $1^{\circ}$ ano do ensino médio; c) LDs que fazem parte da mesma coleção/editora; d) Seções complementares intituladas "CTS".

Assim, a partir da averiguação do GLD (BRASIL, 2014) dos componentes curriculares das Ciências da Natureza, identificamos que o LD de Biologia (LDBio) e Química (LDQui) da coleção "Ser Protagonista" apresentam seções complementares intituladas "Ciência, Tecnologia e Sociedade", ou seja, indicam objetivamente discussões sobre as inter-relações CTS. Em contraponto, o LD de Física não possui seções complementares intituladas "CTS", e mesmo após a averiguação das temáticas dessas seções, consideramos que as mesmas não corroboram com os objetivos de nosso trabalho e, portanto, optamos por não utilizá-lo em nossas análises.

Uma vez que o presente trabalho buscou analisar as seções complementares inseridas em LDs de componentes curriculares diferentes, delimitamos a análise de seções presentes na Unidade 1 de ambos, porque se propõem apresentar a "visão geral" sobre o conhecimento biológico - "Introdução à Biologia" e químico - "Introdução ao estudo da química". A Unidade 1 do LDBio é composta por três capítulos e duas seções complementares CTS e o LDQui possui cinco capítulos e também duas seções complementares CTS.

Estruturamos o processo da pesquisa nas seguintes etapas: 1) Leitura do GLD dos componentes curriculares de Biologia, Física e Química, aprovados pelo PNLD 2015; 2) Identificação dos LDs com seções intituladas "CTS"; 3) Leitura sistemática e análise textual discursiva das seções; 4) Identificação das categorias correlacionadas às dimensões CTS. Apresentamos, no Quadro 1, os LDs selecionados para a análise das seções complementares e o título dos textos.

Quadro 1. Livros didáticos selecionados para análise e as seções complementares

\begin{tabular}{|c|l|l|}
\hline LD & Título/edição/autores & Seções Complementares “CTS” \\
\hline
\end{tabular}




\begin{tabular}{|c|c|c|}
\hline \multirow{5}{*}{ LDBio } & $\begin{array}{c}\text { Biologia: Ensino Médio 10 ano } \\
\text { 2a edição 2013. Ser protagonista - Volume 1; } \\
\text { Coleção Tipo 1; Edições SM. Obra Coletiva. } \\
\text { Editora responsável: Tereza Costa Osorio. }\end{array}$ & $\begin{array}{c}\text { 1- "A responsabilidade social dos } \\
\text { cientistas" } \\
\text { 2- "Gorduras Trans" }\end{array}$ \\
\hline LDQui & $\begin{array}{c}\text { Química: Ensino Médio 1" ano } \\
\text { 2a edição 2013. Ser protagonista - Volume 1 } \\
\text { Coleção Tipo 1; Edições SM. Autor: Murilo } \\
\text { Tissoni Antunes. }\end{array}$ & $\begin{array}{c}\text { 1- "Sobre o natural e o artificial ou } \\
\text { sintético" }\end{array}$ \\
2- "Nem o álcool escapa"
\end{tabular}

FONTE: Elaborado pelas autoras.

As categorias foram fundamentadas nos indicativos de Santos e Mortimer (2009), frente à abordagem de ASC, os quais sinalizam as dimensões propulsoras para discussões sociocientíficas sobre as inter-relações CTS. Para os autores, a abordagem dos ASC visam ressignificar a função social do ensino de ciências para desenvolver atitudes e valores em um processo constante de reflexão sobre o papel social da ciência. Os autores enfatizam que a incorporação dos ASC no currículo favorece discussões de valores e reflexões críticas que possibilitam aos alunos perceberem sua condição no mundo frente aos desafios postos pela ciência e pela tecnologia.

Nesse sentido, as análises dos textos foram organizadas a partir da evidenciação dos ASC em função da prevalência de aspectos históricos, políticos, econômicos, sociais, culturais, ambientais, éticos e morais, identificando e descrevendo as relações estabelecidas pelos autores com o tema abordado. No Quadro 2, apresentamos os ASC e suas respectivas definições.

Quadro 2. Aspectos e Dimensões que fundamentam as discussões sociocientíficas

\begin{tabular}{|c|c|}
\hline $\begin{array}{l}\text { Aspectos } \\
\text { /Dimensões }\end{array}$ & Definições \\
\hline $\begin{array}{l}\text { A- Do trabalho } \\
\text { científico }\end{array}$ & $\begin{array}{c}\text { Indicar elementos relacionados à natureza da ciência, evidenciando as controvérsias } \\
\text { e como é realizado o trabalho científico, seus processos de análise de dados e } \\
\text { interpretação dos resultados, etc. }\end{array}$ \\
\hline $\begin{array}{l}\text { B- Da } \\
\text { tecnologia }\end{array}$ & $\begin{array}{l}\text { Evidenciar como a tecnologia é apresentada e qual ênfase é dada quanto às } \\
\text { dimensões do desenvolvimento tecnológico. }\end{array}$ \\
\hline C- Políticos & $\begin{array}{c}\text { Buscar elementos de cunho político, governamental e legislativo, tais como: } \\
\text { responsabilidade do governo; participação popular em decisões, plenárias; estudo } \\
\text { da legislação, etc. }\end{array}$ \\
\hline D- Históricos & $\begin{array}{l}\text { Buscar elementos relativos à história da ciência, aos debates na comunidade } \\
\text { científica, às contribuições de diferentes cientistas para a validação de teorias, etc. }\end{array}$ \\
\hline E- Econômicos & $\begin{array}{l}\text { Evidenciar elementos que representam a relação da economia com a produção } \\
\text { científico-tecnológica. Por exemplo: aumento/diminuição de postos de trabalho; } \\
\text { investimentos; importação/exportação. }\end{array}$ \\
\hline F- Ambientais & $\begin{array}{l}\text { Indicar elementos ambientais por meio de questões conflituosas frente à relação } \\
\text { homem-ambiente-ciência-tecnologia. Exemplo: Recursos naturais; descarte de } \\
\text { resíduos; poluição; saúde; desastres ambientais, etc. }\end{array}$ \\
\hline
\end{tabular}




\begin{tabular}{|c|c|}
\hline $\begin{array}{c}\text { G- } \\
\text { Socioculturais }\end{array}$ & $\begin{array}{l}\text { Indicar elementos sociais e culturais influenciados pelo desenvolvimento científico- } \\
\text { tecnológico e vice-versa, reconhecendo as especificidades de determinado contexto. } \\
\text { Por exemplo: globalização e cultura; internet e as relações interpessoais; } \\
\text { consumismo; conflitos; interesses; etc. }\end{array}$ \\
\hline $\begin{array}{l}\text { H- Atitudes e } \\
\text { Valores }\end{array}$ & $\begin{array}{l}\text { Indicar elementos voltados ao engajamento, tomada de decisão e responsabilidade } \\
\text { civil. }\end{array}$ \\
\hline $\begin{array}{l}\text { I- Éticos e } \\
\text { Morais }\end{array}$ & $\begin{array}{c}\text { Indicar elementos que expressam atitudes éticas e morais como consciência, } \\
\text { respeito e colaboração. }\end{array}$ \\
\hline
\end{tabular}

FONTE: Elaborado pelas autoras com base nos conceitos de Santos e Mortimer (2009).

As análises foram realizadas em textos das seções intituladas "Ciência, Tecnologia e Sociedade". Foram orientadas pelos pressupostos teóricos anteriormente apresentados (Quadro 2) e pela Análise Textual Discursiva (MORAES; GALIAZZI, 2007). Logo, o método de categorização utilizado foi o dedutivo, ou seja, o corpus desta pesquisa foi analisado a partir de categorias definidas a priori, extraídas dos pressupostos teóricos de Santos e Mortimer (2009).

Após selecionar os textos, procedemos à leitura e à desconstrução de cada um, na perspectiva de identificar e destacar enunciados de interesse, relacionados aos ASC. Esses enunciados (frases, parágrafos ou partes maiores dos textos), foram reunidos em grupos que abarcam elementos comuns e, a partir disso, correlacionados às dimensões dos ASC, sob a forma de metatextos, das descrições e interpretações possibilitadas pela análise. Ressaltamos que as categorias indicadas nesse estudo não esgotam as análises e discussões possíveis de serem realizadas, mas, ajudam-nos a perceber sinalizações de ASC voltadas ao enfoque CTS, explícitas e implícitas nos textos.

No tópico a seguir, serão apresentadas as análises que, inicialmente, descrevem as características gerais referentes à organização do conteúdo das Unidades do LDBio e LDQui. Cabe mencionar que, embora façam parte da mesma coleção, os LDs possuem tipos, modos de organização e linguagem específicos de cada autor, por isso optamos por apresentar as análises de cada LD separadamente.

\section{Análise LDBio}

$\mathrm{Na}$ coleção "Ser Protagonista" do LDBio para o $1^{\circ}$ ano do Ensino Médio, o conteúdo é organizado em unidades e os capítulos em formato de tópicos. As unidades são iniciadas com um pequeno texto chamado "Pra começar" em que são colocados alguns questionamentos aos educandos, os quais visam estimular a reflexão e mobilizam conhecimentos prévios para introdução do tema.

A Unidade 1 é composta por três capítulos: 1) O que é Biologia; 2) As bases químicas da vida e; 3) A origem da vida. Os dois primeiros capítulos são finalizados com a seção denominada "Ciência, Tecnologia e Sociedade" que objetiva, de acordo com suas autoras, prioritariamente a contextualização.

Ao longo dos capítulos, são introduzidos pequenos boxes intitulados "Biologia se discute", "Biologia tem história" e "Saiba mais". Todos os capítulos possuem a seção "Práticas de Biologia". De acordo com a editora responsável, os boxes, associados ao texto principal, contemplam diferentes objetivos e, de modo geral, são complementares, auxiliando a contextualizar o assunto em relação ao cotidiano do educando, mostrando 
interações com outras disciplinas e pontos de vista diferentes ou fornecendo informações adicionais. Em relação às seções, o objetivo é promover a fixação de um conteúdo por meio de experimentos, atividades e textos contemporâneos (OSORIO, 2013).

O texto da seção "Ciência, Tecnologia e Sociedade", do primeiro capítulo é intitulado: "A responsabilidade social dos cientistas"4. O tema explora não somente elementos sobre o progresso e o bem-estar da humanidade ao sinalizar a importância do desenvolvimento científico-tecnológico para a sociedade, mas também suas consequências negativas como podemos identificar no trecho do primeiro parágrafo: “[...] em alguns momentos da história universal recente, o uso do conhecimento científico e tecnológico foi responsável por grandes desastres e tragédias para a humanidade, entre os quais se destaca o lançamento de bombas atômicas [...]" (OSORIO, 2013, p. 23).

O trecho supracitado apresenta elementos textuais que relacionam a produção científico-tecnológica à grandes tragédias da humanidade exemplificando o lançamento da bomba atômica. Nesse caminho, é possível promover discussões sobre a produção científico-tecnológica e as questões políticas envolvidas nesse evento histórico.

Ao ampliar tais discussões poderão ser identificados aspectos da política do governo americano da década de 1945, cenário da segunda guerra mundial. Além disso, estabelecer relações entre o investimento em Ciência e Tecnologia (CT) no que compete à produção de armas bélicas, atrelado às questões políticas e socioeconômicas do país. Problematizar esse evento histórico também poderia direcionar as discussões acerca do investimento em CT no contexto brasileiro a partir de um resgate histórico dos governos questionando interesses políticos e econômicos. Deste modo, podemos identificar as categorias: do trabalho científico (categoria A); tecnologia (categoria B); política (categoria C) e; históricos (categoria D).

As orientações didáticas contidas no manual dos professores (OSORIO, 2013) para a abordagem do referido texto, evidenciam que o objetivo é gerar um debate em torno do tema, "Espera-se que os alunos reconheçam todas essas instâncias como corresponsáveis pelos rumos das diferentes culturas humanas" (OSORIO, 2013, p. 343). Explicam também que os professores podem ampliar as discussões por meio da proposição de um projeto multidisciplinar envolvendo as áreas de História e Filosofia com foco nas diferentes culturas humanas e no papel do conhecimento científico.

A partir dessa sugestão didático-pedagógica, podemos inferir que as orientações do manual sobre a abordagem da seção analisada assumem três dimensões inerentes ao enfoque CTS: 1) ao enfatizar aspectos do trabalho científico, ao se propor a discussão do papel da ciência, de sua produção e de seus impactos; 2) de aspectos políticos suscitados a partir das discussões sobre os motivos que levaram desde a produção até o lançamento da bomba atômica e; 3) de aspectos históricos ao evidenciar eventos relativos à produção científico-tecnológica.

Bazzo (1998) afirma que os estudos acerca das inter-relações CTS contribuem com a ampliação da percepção da sociedade por parte dos estudantes sobre os condicionantes e implicações da pesquisa e do desenvolvimento científico e tecnológico. Nesse sentido,

\footnotetext{
4 O texto, publicado no LDBio, foi retirado da página do Instituto de Estudos Avançados (IEA) da Universidade de São Paulo. O IEA foi criado em 1986 e trata-se de um órgão de integração destinado à pesquisa e discussão, de forma abrangente e interdisciplinar, das questões fundamentais da ciência e da cultura. (http://www.iea.usp.br/iea/quem-somos).
} 
identificamos no trecho do segundo parágrafo, discussões sobre o conceito de sociedade, meio ambiente e os impactos científicos-tecnológicos os quais denotam aspectos do desenvolvimento tecnológico (categoria B) e aspectos ambientais (categoria F): “[...] há várias questões a considerar sobre as consequências sociais no desenvolvimento científico e tecnológico: a aplicação para fins militares; o impacto do avanço tecnocientífico no meio ambiente [...]" (OSORIO, 2013, p. 23).

No terceiro parágrafo: “A ideia positivista de que o desenvolvimento científico e tecnológico atua sempre no sentido de uma solução benéfica para a humanidade tem sido contestada pelos fatos" (OSORIO, 2013, p. 23), incita discussões sobre aspectos voltados à compreensão de elementos relacionados à natureza da ciência, evidenciando controvérsias sociocientíficas (categoria A) quando é indicado a elucidação de fatos da história da humanidade que sinalizam contestar o mito salvacionista da ciência (categoria D).

No quarto parágrafo, o texto é finalizado com o intuito de promover discussões relacionadas às técnicas destinadas à cura e prevenção de enfermidades e a produção de alimentos. Nesse sentido, são indicadas discussões sobre bioética, Organismos Geneticamente Modificados (OGM), biossegurança e uso de células-tronco para fins terapêuticos.

Após o texto, há um box intitulado "Para discutir" que contém duas questões para que os educandos discutam com os colegas e respondam. Na primeira questão, o educando é orientado a citar exemplos de descobertas científicas que favoreceram o bem-estar ou a expectativa de vida da grande parte da população mundial. A segunda incita o educando a opinar sobre a responsabilidade das consequências advindas do uso de descobertas científicas destacando três opções: o pesquisador, o governo ou a sociedade. Esses questionamentos poderão ser abordados pelos professores com vistas ao engajamento e à responsabilidade civil mediante a participação em decisões tecnocráticas (categoria $\mathrm{H}$ ), e indicadores éticos e morais como consciência, respeito e colaboração (categoria I).

O texto da seção "Ciência, Tecnologia e Sociedade", referente ao segundo capítulo do LDBio, é intitulado "Gordura trans" (OSORIO, 2013, p. 43). Encontra-se no formato do tipo questionário, com perguntas e respostas, que abarcam os tópicos julgados mais importantes em relação ao entendimento do tema, sendo eles: o que é? Por que recebem esse nome? Que tipos de alimentos possuem esse tipo de gordura? Devemos ou não consumi-la? Quais os riscos para a saúde? Qual sua vantagem de produzi-la? Já existem alimentos livres desse tipo dessa gordura?

Embora o texto tenha caráter informativo, acreditamos que o mesmo poderá contribuir com a problematização do tema, visto que está diretamente relacionado à produção de alimentos a partir do processo industrial e, portanto, ao desenvolvimento científico-tecnológico em relação à saúde humana. Nesse viés, o texto introduz questões de cunho reflexivo sobre o consumo e a saúde, como destacado nos questionamentos sobre a necessidade em se consumir a "gordura trans", as taxas recomendadas, os malefícios e a vantagem de se produzir alimentos com esse tipo de gordura.

As questões indicadas propõem discussões referentes ao poder de decisão do consumidor em comprar ou não alimentos industrializados que possuam esse tipo de

\footnotetext{
${ }^{5}$ Trata-se de um conteúdo publicado no site da Agência Nacional de Vigilância Sanitária (ANVISA) com o título "Gordura Trans" da coluna "respostas à imprensa". Disponível em: http://portal.anvisa.gov.br.
} 
gordura em sua composição. Corroborando com o alerta indicado no texto, entendemos que a análise dos malefícios causados pelo consumo desses alimentos, bem como a necessidade de informar a sociedade sobre a presença desses componentes nos rótulos de produtos alimentícios, é fundamental para que os educandos tenham conhecimento do que está consumindo, dos riscos à saúde e de que, a partir disso, saibam realizar suas escolhas.

Nesse sentido, evidenciamos aspectos de cunho político (categoria C) no que compete às responsabilidades de órgãos governamentais em fiscalizar produtos que em seus rótulos que contenham as informações nas tabelas nutricionais sobre os alimentos, como observado nos trechos a seguir: [...] "Nas prateleiras dos supermercados é possível encontrar produtos denominados trans free [livres de gordura trans]"; (OSORIO, 2013, p. 43) e ainda: "[...] A Organização Mundial da Saúde (OMS) recomenda que a ingestão de gordura trans não ultrapasse 1\% do valor calórico da dieta [...]" (OSORIO, 2013p. 43).

Ainda que a rotulagem nutricional integre a política de alimentação e nutrição com foco na promoção de práticas alimentares mais saudáveis, é necessário que os cidadãos saibam interpretar esses rótulos, de modo que as informações neles contidas possam servir para a tomada de decisão sobre o tipo de alimentação mais adequada aos objetivos e às necessidades de cada um (NEVES; GUIMARÃES; MERÇON, 2008).

Nesse sentido, além das questões presentes no texto, o box "Para discutir" possui três perguntas que estimulam o educando a compreender como analisar rótulos nutricionais de dois alimentos similares e também solicitam a opinião sobre a influência das informações nutricionais em suas escolhas. Deste modo, ter o conhecimento sobre o tipo de "gordura trans", seus malefícios à saúde humana quando consumidas acima dos níveis recomendados pela OMS, são aspectos do enfoque CTS visto que se problematiza a relação de elementos da produção científica, o consumo e o poder de tomar decisões (categoria $\mathrm{H}$ ).

\section{Análise LDQui}

O LDQui da coleção "Ser Protagonista" (ANTUNES, 2013), assim como o LDBio, possui, no canto superior da página inicial dos capítulos, a apresentação dos conteúdos que serão abordados. Há boxes intitulados a "Química tem história" e "Saiba mais". A Unidade 1, foco do nosso estudo, apresenta dois capítulos: 1) Química: objeto de estudo e aplicações e; 2) Unidades de medida. Para cada um desses capítulos, há uma seção "Ciência, Tecnologia e Sociedade": 1) "Sobre o natural e o artificial ou sintético" e; 2) "Nem o álcool escapa".

O texto "Sobre o natural e o artificial ou sintético"6 consiste em abordar os equívocos da população em relação à linguagem científica, quando se trata dos termos "natural", "artificial" e "sintético". Tais expressões apresentam sentidos diferentes e são comumente confundidas.

Para trabalhar os referidos conceitos, o texto explica que materiais sintéticos frequentemente são associados às substâncias tóxicas prejudiciais à saúde e ao meio ambiente. Em seguida, cita exemplos de materiais naturais que possuem em sua composição substâncias com alto grau de toxicidade: [...] "muitos frutos, folhas e raízes,

\footnotetext{
${ }^{6}$ Fragmentos do capítulo "Sobre a naturalidade das coisas" (p. 22 - 29) de autoria de Mary Catherine Bateson, retirado do livro "As coisas são assim" dos organizadores John Brockman e Katinka Matson, tradução de Dhiogo Meyer e Suzana Couto, 4ª edição, 2008.
} 
contém em sua composição esse tipo de substância que, se ingerida ainda em pequenas quantidades, pode levar uma pessoa à morte [...]" (BATESON, 2008, p. 20).

Nas orientações didáticas indicadas no manual dos professores, sugere-se que seja problematizado o fato de que muitas plantas encontradas na natureza são tóxicas e que, em contraposição, materiais sintetizados na indústria como, por exemplo, os fármacos, trazem benefícios para a população. Sobre os benefícios provenientes da produção científicotecnológica, observamos no trecho recortado do texto:

[...] Também não se pode dizer que todo produto artificial causa prejuízos à saúde. Populações humanas existem hoje graças à interferência maciça do ser humano na natureza. Essa interferência se dá, por exemplo, por meio do desenvolvimento de técnicas agrícolas, as quais garantem a produção de alimentos; de tecnologia médicas e farmacêuticas relacionadas à produção de medicamentos capazes de controlar inúmeras doenças [...] (BATESON, 2008, p. 20, grifo nosso).

No trecho acima, são evidentes as questões sobre a natureza do conhecimento científico e do processo de desenvolvimento tecnológico no contexto socioambiental. Se analisado separadamente do contexto, podemos inferir uma interpretação unilateral de ciência e tecnologia em uma perspectiva salvacionista, crença em que CT podem solucionar todos os problemas da humanidade e de determinismo tecnológico, ao considerar que a tecnologia determina de maneira direta, unidirecional e positiva o desenvolvimento socioeconômico de uma população.

Cabe neste momento ampliar as discussões no sentido de questionar a quem se destinam essas técnicas, quem são os beneficiados e quais as consequências provenientes do desenvolvimento para a sociedade. Esclarecemos ainda, que não se trata de ser "contra ou a favor do uso da tecnologia, mas de uma educação em que os alunos possam refletir sobre a sua condição no mundo frente aos desafios postos pela ciência e tecnologia" (SANTOS; MORTIMER, 2009, p. 193). Nesse caminho, dando prosseguimento à leitura do texto, no parágrafo seguinte, a autora retoma a discussão e argumenta que, provavelmente, muitos artefatos desenvolvidos pela indústria química também prejudicaram o meio ambiente e a saúde humana:

[...] entre os exemplos está o DDT, um pesticida utilizado no combate ao mosquito da malária e do tifo. Seu desenvolvimento rendeu ao suíço Paul h. Muller, em 1948, o prêmio nobel da medicina. Contudo, a partir da década de 1970, seu uso foi proibido nos Estados Unidos e em vários países, pois estudos comprovaram alta toxicidade [...] (BATESON, 2008, p. 20, grifo nosso).

Como o desdobramento desse trecho, a autora exemplifica casos de câncer, contaminação de alimentos, partos prematuros e danos neurológicos, consequências do contato com a alta toxicidade do DDT. Ao observar o trecho supracitado, indicamos aqueles relacionados ao desenvolvimento científico-tecnológico (categoria B) ao considerar que o DDT é um produto da ciência e da tecnologia; os políticos (categoria C), no sentido de sua proibição e sua fiscalização e; os ambientais (categoria F), frente ao acúmulo de DDT, no que compete à saúde e ao meio ambiente.

Nessa direção, como suporte aos professores, ao final do texto, há um box intitulado "Analise e Discuta", composto por questionamentos referentes ao tema. Uma das questões está direcionada ao uso do DDT e suas consequências, o que, então, pode levar à promoção de debates em sala de aula com ênfase: a) nas relações de poder que existiu por 
muitos anos no lobby da indústria química relativas a esse inseticida (categoria E); b) no contexto histórico em que se deu a produção do DDT (categoria D); c) nos aspectos socioambientais envolvidos (categoria F).

O segundo texto, intitulado "Nem o álcool escapa", tem por finalidade proporcionar aos educandos o entendimento de que a falta ou excesso de álcool em relação aos valores estabelecidos pela ANP (Agência Nacional de Petróleo) compromete a qualidade do combustível que chega aos consumidores brasileiros. Sendo assim, inicialmente, o texto faz uma chamada à questão do etanol advindo da cana-de-açúcar adulterado em alguns postos de combustível: "combustível da cana adulterado ganha os postos e torna carros flexíveis duas vezes mais vulneráveis às bombas batizadas" (DUQUE; CALMON, 2005, p. 30, grifo nosso). O texto é iniciado com o seguinte trecho apresentado: "Se a adulteração da gasolina já é um fantasma antigo, agora os proprietários dos carros bicombustíveis têm uma preocupação a mais: o álcool 'batizado' [...]" (DUQUE; CALMON, 2005, p. 30, grifo nosso).

A adulteração do combustível de cana é problematizada em termos do que ela significa para o mercado, para os carros e consumidores, como identificado no trecho a seguir: "[...] Para o mercado, a alteração significa sonegação de impostos e concorrência desleal. Para o carro, uma doença que ataca todo o circuito percorrido pela mistura [...]" (DUQUE; CALMON, 2005, p. 30). Sonegar impostos representa a ganância das empresas em superar o seu ganho frente aos impostos cobrados pelo Governo, assim, consideramos evidentes nessa discussão os aspectos econômicos, políticos, éticos e morais (categorias $\mathrm{C}$, E e I).

Referente a esse texto, o manual sugere aos professores que "aproveite o momento para promover uma reflexão sobre a ideia de 'levar vantagem' em situações que prejudicam outras pessoas" (ANTUNES, 2013, p. 15, grifo nosso). Essa sugestão está diretamente relacionada aos aspectos éticos e morais (categoria I), e criam condições para a difusão de valores assumidos como fundamentais ao interesse social e aos direitos dos cidadãos.

O texto é finalizado com a informação sobre como o consumidor pode identificar um combustível adulterado: "[...] A ANP bolou uma tática simples: acrescentar uma tintura laranja ao álcool anidro. Assim, se a bomba estiver colorida, o combustível que está ali não é álcool hidratado [...]" (DUQUE; CALMON, 2005, p. 30). A mobilização desse tipo de conhecimento, junto às discussões econômicas e éticas colocadas ao longo do texto possibilita um trabalho educativo que incentiva os educandos a assumirem um posicionamento crítico frente às questões éticas e morais (categoria I) que abarcam o tema.

Seguido dessa mobilização, o último parágrafo do texto também apresenta um apelo para que o consumidor se previna de abusos e fraudes dos postos de combustíveis: "[...] olho na bomba: se o álcool estiver colorido, rejeite. Só serve se for transparente. Procure abastecer em posto de confiança, desconfie de preços excessivamente baixos e sempre peça nota fiscal [...]" (DUQUE; CALMON, 2005, p. 30). Desse apelo, pode-se favorecer o desenvolvimento do pensamento crítico quanto às questões políticas, econômicas e éticas sobre os postos de combustíveis.

\footnotetext{
7 Fragmentos do capítulo "Sobre a naturalidade das coisas" (p. 22 - 29) de autoria de Mary Catherine Bateson, retirado do livro "As coisas são assim" dos organizadores John Brockman e Katinka Matson, tradução de Dhiogo Meyer e Suzana Couto, $4^{\mathrm{a}}$ edição, 2008.
} 
Reforçando essa possibilidade, o box "Analise e Discuta" coloca em debate se os densímetros acoplados às bombas garantem, ou não, ao consumidor a qualidade do combustível. Além disso, apresenta uma situação hipotética relacionando o tanque cheio com o instrumento de medida testado e aprovado pela fiscalização e questiona se o consumidor adquiriu ou não a quantidade indicada na bomba. Essa pergunta é orientadora de um enfoque conceitual com o propósito de, a partir do conhecimento sobre unidades de medida, o educando tenha conhecimento sobre como exigir a quantidade correta.

Consideramos que o conteúdo do texto favorece discussões sociocientíficas visto que incitam aspectos relacionados ao meio ambiente sobre a emissão de gases provenientes da combustão dos veículos (categoria F); às tecnologias voltadas à produção de carros bicombustíveis (categoria B); econômicos e políticos sobre os impostos e as consequência do uso de combustíveis adulterados nos motores (categorias $\mathrm{C}$ e E) e; éticos e morais em referência a conduta irregular de postos de combustíveis em vender produtos irregulares aos consumidores (categoria I).

No Quadro 3, sintetizamos as categorias voltadas às discussões sociocientíficas identificadas nos textos do LDBio e LDQui. Observa-se que os aspectos políticos (categoria C) foram observados nos quatro textos analisados, sinalizando situações relacionadas à responsabilidade do governo e da participação popular em decisões. Em referência aos aspectos socioculturais (categoria G), estes, por sua vez, não foram observados de forma explícita em nenhum dos textos analisados, o que não significa dizer que os professores não possam abarcá-los durante as discussões, pois todos os textos possibilitam a indicação de elementos sociais e culturais influenciados pelo desenvolvimento científico-tecnológico e vice-versa.

Quadro 3: ASC identificados nos textos analisados

\begin{tabular}{|c|c|c|c|c|c|c|c|c|c|}
\hline Textos & \multicolumn{7}{|c|}{ Aspectos Sociocientíficos* } \\
\hline LDBio & A & B & C & D & E & F & G & H & I \\
\hline 1 & $\mathrm{x}$ & $\mathrm{x}$ & $\mathrm{x}$ & $\mathrm{x}$ & & $\mathrm{x}$ & & $\mathrm{x}$ & $\mathrm{x}$ \\
\hline 2 & & & $\mathrm{x}$ & & & & & $\mathrm{x}$ & \\
\hline LDQui & $\mathrm{A}$ & $\mathrm{B}$ & $\mathrm{C}$ & $\mathrm{D}$ & $\mathrm{E}$ & $\mathrm{F}$ & $\mathrm{G}$ & $\mathrm{H}$ & $\mathrm{I}$ \\
\hline 1 & & $\mathrm{x}$ & $\mathrm{x}$ & $\mathrm{x}$ & $\mathrm{X}$ & $\mathrm{x}$ & & $\mathrm{x}$ & \\
\hline 2 & & $\mathrm{x}$ & $\mathrm{x}$ & & $\mathrm{X}$ & & & $\mathrm{x}$ & $\mathrm{x}$ \\
\hline
\end{tabular}

*Aspectos das categorias: A (Trabalho Científico); B (Tecnologia); C (Políticos); D (Históricos); E (Econômicos); F (Ambientais); G (Socioculturais); H (Atitudes e Valores); I (Éticos e Morais). Fonte: Elaborado pelas autoras.

Abordar aspectos socioculturais em discussões acerca das inter-relações CTS pressupõe o entendimento sobre a interação pessoas-ambiente-sociedade que indica o tipo das organizações sociais em meio às culturas que, por sua vez, influenciam as regras morais de comportamento e as instituições educativas, sendo elas formais ou não-formais.

$\mathrm{O}$ aspecto sociocultural é fundamentado pelo reconhecimento de que as diversas ciências contribuem na análise das especificidades de determinado contexto, tais como: 
sociologia, antropologia, história, educação, política, etc. e, envolvem elementos ideológicos, de comunicação e linguagem, de estrutura do pensamento, entre outros, que favorecem a compreensão das especificidades de dada comunidade/sociedade.

As análises nos permitem inferir que os ASC identificados, assim como as orientações dos manuais dirigidos aos professores de como trabalhar os textos, podem possibilitar debates em sala de aula, de modo que os educandos compartilhem suas vivências cotidianas e fundamentem seus argumentos sobre o desenvolvimento científicotecnológico.

Entretanto, ressaltamos que as discussões adquirem potencial considerável, desde que os professores tenham clareza dos direcionamentos dados a cada um desses aspectos/dimensões, estabelecendo uma relação mais horizontal e dialogada com os educandos.

\section{CONSIDERAÇÕES FINAIS}

As análises realizadas nos permitiram identificar os ASC nos textos de seções complementares intituladas "Ciência, Tecnologia e Sociedade" dos LDBio e LDQui da coleção "Ser Protagonista". Todos os textos analisados suscitam discussões de aspectos contemplados nas categorias elaboradas a priori para esse corpus de estudo, uns mais frequentes que outros, mas com potencialidade suficiente para orientar discussões acerca das inter-relações CTS.

Os temas abordados pelos textos favorecem discussões de controvérsias sociocientíficas em diferentes direções, como, por exemplo, sobre o desenvolvimento científico-tecnológico e os impactos socioambientais, ou ainda, em relação ao consumo de determinados alimentos ou utilização de produtos e a saúde humana, tomada de decisão, valores éticos e morais. Nessa direção, os conteúdos escolares poderão ser mobilizados em função de temas problematizados e contextualizados, ampliando a compreensão sobre a relação entre ciência, tecnologia, sociedade e ambiente, na medida em que permitam que os educandos avaliem a complexidade de cada tema/questão, em um viés investigativo sobre as dimensões inerentes à análise das problemáticas incitadas.

Ressaltamos que a abordagem dos ASC no ensino de ciências não se restringe aos conteúdos específicos das Ciências da Natureza, porque, apesar de serem relevantes para a apropriação do conhecimento da natureza da ciência, não são suficientes para abarcar as múltiplas dimensões relativas aos temas, que são multidisciplinares por sua natureza conceitual e por isso exigem um enfoque interdisciplinar.

A garantia para esses direcionamentos ao processo de ensino e aprendizagem requer investir na formação de professores de ciências no que se refere à compreensão do LD em suas múltiplas facetas; da natureza da ciência e; do conceito de "currículo-aberto" às questões sociocientíficas globais, regionais e locais.

As estratégias de ação com vistas à formação sociopolítica deverão possibilitar o entendimento dos conteúdos científicos situados em uma perspectiva problematizadora, contextualizada e interdisciplinar e, por isso, devem ser organizadas de forma sistemática com a definição prévia de objetivos, metodologias e avaliações. Nesse sentido, consideramos o Programa Institucional de Bolsas de Iniciação à Docência (PIBID) um espaço profícuo para tais projeções formativas, visto que comungam professores 
formadores, professores em formação inicial e em exercício que direcionam suas ações aos educandos em um processo com tempos e modos diferentes do currículo tradicional.

Por fim, reconhecemos a limitação desta pesquisa frente à importância em se averiguar como tais seções complementares são abordadas em salas de aulas de ciências. Por isso, é necessário desenvolver pesquisas que se ocupem da análise sobre a prática de professores ao usar o LD em sala de aula, e dos discursos e concepções de alunos e professores sobre o referido instrumento. Em continuidade, apontar importantes elementos a serem considerados na elaboração do LD e na formação de professores em referência ao enfoque CTS.

\section{REFERÊNCIAS}

ANTUNES, M. T. Ser Protagonista (Manual do professor): Química, $1^{\circ}$ ano: ensino médio. 2 ed. São Paulo: Edições SM, 2013.

ABREU, R. G; GOMES, M. M; LOPES, A. C. Contextualização e Tecnologias em Livros didáticos de Biologia e Química. Investigações em Ensino de Ciências, v. 10, n. 6, pp. 405417, 2005.

BAZZO, W. A. Ciência, Tecnologia e Sociedade: e o contexto da Educação Tecnológica. Florianópolis: Ed. da UFSC, 1998. 319 p.

; VON LINSINGEN, I.; PEREIRA, L. T. V. Introdução aos estudos CTS. Madri: Organização dos Estados Ibero-americanos para a Educação, a Ciência e a Cultura (OIE), 2003.

BITTENCOURT, C. M. F. Em foco: história, produção e memória do livro didático. Revista Educação e Pesquisa, v. 30, n. 3. São Paulo: EDUSP. Set/dez. 2004.

BRASIL. Lei de Diretrizes e Bases da Educação Nacional. Lei no 9.394, 1996.

. Ministério da Educação. Secretaria da Educação Média e Tecnológica. Parâmetros Curriculares Nacionais: Ensino Médio. Brasília, 1998.

Fundo Nacional de Desenvolvimento da Educação. Secretaria de Educação Básica. Edital de convocação para inscrição no processo de avaliação e seleção de coleções didáticas para o Programa Nacional do Livro Didático/ PNLD 2015. Brasília: 2015.

. Guia de livros didáticos: PNLD 2015 - Biologia. Brasília: Ministério da Educação, Secretaria de Educação Básica, 2014a. 80p.

: PNLD 2015 - Física. Brasília: Ministério da Educação, Secretaria de Educação Básica, 2014b. 108p.

: PNLD 2015 - Química. Brasília: Ministério da Educação, Secretaria de Educação Básica, 2014c. 60p.

: PNLD 2015 - Apresentação: Ensino Médio. Brasília: Ministério da Educação, Secretaria de Educação Básica, 2014. 52p.

CARNEIRO, M. H. S.; SANTOS, W. L. P.; MÓL, G. S. Livro didático inovador e professores: uma tensão a ser vencida. Ensaio: Pesquisa em Educação em Ciências, v. 7, n. 2, pp. 101-113, 2005. 
CHOPPIN, A. História dos livros e das edições didáticas: sobre o estado da arte. Educação e Pesquisa, v. 30, n. 3, pp. 549-566, 2004.

FORGIARINI, M. S.; AULER, D. A abordagem de temas polêmicos na educação de jovens e adultos: o caso do "florestamento" no Rio Grande do Sul. Revista Electrónica de Enseñanza de las Ciencias, v. 8, n. 2, pp. 399-421, 2009.

HÖFLING, E. M. Notas para discussão quanto à implementação de programas de governo: em foco o Programa Nacional do Livro Didático. Educação e Sociedade [online], v. 21, n.70, pp.159-170, 2000.

LINHARES, E. F; REIS, P. Formar futuros professores para a ação sociopolítica no contexto da educação em ciências. Revista Brasileira de Ensino de Ciência e Tecnologia, Ponta Grossa, v. 11, n. 2, pp. 86-104, 2018.

MACHADO, A. H.; MOL, G. S.; ZANON, L. B. O Livro Didático como Possibilidade de Mediação de Inovações na Sala de Aula. MOL, G. S. (Org.) Ensino de Química: Visões e Reflexões. Ijuí: Editora Unijuí, 2012. pp. 27-64.

MORAES, R.; GALIAZZI, M. C. Análise textual discursiva. Ijuí: Editora Unijuí, 2007.

MUENCHEN, C.; AULER, D. Configurações curriculares mediante o enfoque CTS: desafios a serem enfrentados na educação de Jovens e Adultos. Ciência \& Educação, v. 13, n. 3, pp. 421-434, 2007.

NASCIMENTO, T. G.; VON LINSINGEN, I. Articulação entre o enfoque CTS e a pedagogia de Paulo Freire como base para o ensino de Ciências. Convergência (Toluca). v. 13, pp. 95-116, 2006.

MEGID-NETO, J; FRACALANZA, H. O livro Didático de Ciências: problemas e soluções. Ciência \& Educação, v. 9, n. 2, pp. 147-157, 2003.

NEVES, A. P.; GUIMARAES, P. I. C; MERÇON, F. Interpretação de rótulos de alimentos no ensino de química. Química Nova na Escola, v.31. n. 1.pp. 34-38, 2009.

RICARDO, E. C. Educação CTSA: obstáculos e possibilidades para sua implementação no contexto escolar. Ciência \& Ensino, v. 1, número especial, nov. 2007.

ROEHRIG, S. A. G; CARMARGO, S. Educação com Enfoque CTS em documentos curriculares regionais: o caso das diretrizes curriculares de física do estado do Paraná. Ciência e Educação (Bauru), v. 20, n. 4, pp. 871-887, 2014.

SANTOS, W. L. P. Educação científica humanista em uma perspectiva freireana: resgatando a função do ensino de CTS. Alexandria, v.1, n.1, pp. 109-131, 2008.

SANTOS, W. L. P.; MORTIMER, E. F. Uma análise de pressupostos teóricos da abordagem C-T-S (Ciência-Tecnologia-Sociedade) no contexto da educação brasileira. Ensaio: pesquisa em educação em ciências, v. 2, n. 2, pp. 133-162, 2002.

; __ Abordagem de Aspectos Sociocientíficos em aulas de Ciências: possibilidades e limitações. Investigações em Ensino de Ciências, v. 14, n. 2, pp. 191-218, 2009.

SILVA, K. M. A. Abordagem CTS no Ensino Médio: Um estudo de caso da prática pedagógica de professores de Biologia. Dissertação de mestrado. 2010. $161 \mathrm{f}$. (Mestrado em Educação em Ciências e Matemática) - Universidade Federal de Goiás, Goiânia, 2010. 
STRIEDER, R. B. Abordagens CTS na educação científica no Brasil: sentidos e perspectivas. Tese (Doutorado em Ensino de Física) - Faculdade de Educação, Instituto de Física, Instituto de Química e Instituto de Biociências, Universidade de São Paulo, 2012.

; SILVA, K. M. A.; SOBRINHO, M. F; SANTOS, W. L. P. A Educação CTS possui respaldo em documentos oficiais brasileiros? ACTIO: Docência em Ciências, Curitiba, v. 1, n. 1, pp. 87-107, jul./dez., 2016.

OSORIO, T. C. Ser protagonista (Manual do professor): Biologia, $1^{\circ}$ ano: ensino médio. 2. ed. São Paulo: Edições SM, 2013.

VASCONCELOS, S. D; SOUTO, E. O Livro Didático de Ciências no Ensino Fundamental: proposta de critérios para análise do conteúdo zoológico. Ciência \& Educação, v. 9, n. 1, pp. 93-104, 2003.

Recebido em: 01/12/2018

Aprovado em: 08/01/2019 